\title{
PRODUÇÃO, COMPOSIÇÃO QUÍMICA E DEGRADABILIDADE RUMINAL IN SITU DE CULTIVARES DE CANA-DE-AÇÚCAR
}

\author{
PRODUCTION, CHEMICAL COMPOSITION AND RUMINAL IN SITUDEGRADABILITY OF \\ THE SUGARCANE VARIETIES
}

\author{
Pádua, F.T. ${ }^{1}$, Fontes, C.A.A. ${ }^{2}$, Thiébaut, J.T.L. ${ }^{2}$, Deminicis, B.B. ${ }^{3}$, Almeida, J.C.C. ${ }^{4}$ \\ e Araujo, R.P. ${ }^{2}$
}

\begin{abstract}
${ }^{1}$ Instituto Federal do Rio de Janeiro-IFRJ. Campus de Pinheiral, RJ. Brasil. fabio.padua@ifrj.edu.br 2Universidade Estadual do Norte Fluminense. Campos dos Goytacazes, RJ. Brasil. ${ }^{3}$ Universidade Federal do Espírito Santo. Alegre, ES. Brasil.

${ }^{4}$ Universidade Federal Rural do Rio de Janeiro. Seropédica, RJ. Brasil.
\end{abstract}

\section{PalaVRas chaVe adicionais}

Análise de agrupamento. Componentes principais. Saccharum officinarum.

\section{RESUMO}

Foram avaliadas a produção, composição química e degradabilidade ruminal in situ de variedades de cana-de-açúcar in natura. Foram objeto do estudo as variedades: RB867515, RB835486, RB758540, RB72454, RB928064, RB845210, RB739735, RB855536, RB855113, RB835054, RB858927, RB765418, SP81-3250, SP80-1816, SP80-3280, SP90-3414, SP91-1049, SP80-1842, SP79-2233, SP90-1638, SP83-2847, SP83-5073, SP86-155 e CB44-74. Os aspectos agronómicos e a composição bromatológica foram avaliados em um delineamento em blocos casualizados com 4 repetições. Os resultados obtidos foram submetidos aos testes de normalidade, multi-colinearidade, componentes principais e agrupamento pelo teste de Scott Knott $(p<0,05)$. As variáveis que mais contribuíram para discriminar os grupos foram: produção de biomassa por hectare $(91,10 \%)$, fibra em detergente neutro $(4,54 \%)$, fração indegradável (I) $(3,27 \%)$ e hemicelulose $(1,08 \%)$. A análise de agrupamento possibilitou discriminar três grupos de variedades de canade-açúcar. Foram selecionadas as variedades RB855536, RB835486 e SP80-1842.

\section{SUMMARY}

In this experiment the production, chemical composition, and in situ ruminal degradability of

Recibido: 18-5-09. Aceptado: 23-2-12.

\section{AdDitional KEYWORDS}

Grouping analysis. Main components. Saccharum officinarum.

sugarcane varieties were evaluated. They were included in the research the varieties: RB867515, RB835486, RB758540, RB72454, RB928064, RB845210, RB739735, RB855536, RB855113, RB835054, RB858927, RB765418, SP81-3250, SP80-1816, SP80-3280, SP90-3414, SP91-1049, SP80-1842, SP79-2233, SP90-1638, SP83-2847, SP83-5073, SP86-155 and CB44-74. The agronomic characteristics and bromatological composition were evaluated following a randomized block design, with four replicates. The results obtained for the different variables were submitted to the tests of normality, multicollinearity, main components and the grouping Scott Knott test at the $5 \%$ significancy level. The most important variables for group discrimination were biomass production per ha $(91,1 \%)$, neutral detergent fiber $(4,54 \%)$, the non degradable fraction (I) $(3,27 \%)$ and hemicelulose $(1,08 \%)$. The grouping analysis permitted to discriminate three groups of varieties of sugarcane. The varieties RB855536, RB835486 and SP80-1842 were selected, based on the variables that had the higher discrimination power.

\section{INTRODUÇÃO}

A cana-de-açúcar é a principal forrageira utilizada na suplementação alimentar dos rebanhos bovinos de corte e leiteiro e por 
criadores de ovinos das regiões norte e noroeste fluminenses. A composição química e a DRIS (degradabilidade ruminal in situ) da cana estão diretamente relacionadas com estádio de maturação, época de corte e proporção de parte aérea (olhadura). Na cana-de-açúcar a olhadura contém proporcionalmente maior teor de FDN que o colmo, onde canas ideais para a alimentação animal devem apresentar maior proporção de colmo em detrimento a olhadura.

Com este trabalho, objetivou-se avaliar variedades de cana-de-açúcar cultivadas no norte e noroeste fluminense apartir dos aspectos da produção de matéria natural, sacarose, composição química e da DRIS e selecionar as variedades mais satisfatórias para utilização na alimentação animal.

\section{MATERIALE MÉTODOS}

O experimento compreendeu uma série de etapas conduzidas no Horto Municipal de Quissamã, na Unidade de Apoio à Pesquisa em Zootecnia do Laboratório de Zootecnia e Nutrição Animal (LZNA) da Universidade Estadual do Norte Fluminense e na Universidade Federal Rural do Rio de Janeiro.

As variedades de cana-de-açúcar estudadas foram: RB867515; RB835486; RB758540; RB72454; RB928064; RB845210; RB739735; RB855536;RB855113; RB835054; RB858927; RB765418; SP81-3250; SP801816; SP80-3280; SP90-3414; SP91-1049; SP80-1842; SP79-2233; SP90-1638; SP832847; SP83-5073; SP86-155 e CB44-74, provenientes de um projeto de pesquisa realizado no município de Quissamã fruto do convênio entre a Prefeitura Municipal de Quissamã e a UFRRJ.

As amostras utilizadas tiveram origem em um experimento conduzido em delineamento em blocos casualizados com 24 variedades (tratamentos), em 4 blocos, com 4 repetições. As variedades foram plantadas em 4 linhas com $5 \mathrm{~m}$ de comprimento em cada parcela experimental, com espaçamento de
1,3 m entre linhas. As variedades de canade-açúcar foram colhidas aos 12 meses de idade ( $1^{\text {a }}$ soca), sendo cortadas a uma altura de 10 centímetros do solo. Para composição da amostra de cada variedade avaliada, as duas linhas de cada extremidade da parcela foram desprezadas sendo consideradas como bordadura, das duas linhas centrais consideradas com área útil da parcela, as plantas de cana completas (colmo + parte aérea) foram cortadas a uma altura de $5 \mathrm{~cm}$ do solo, pesadas e determinada a produção de matéria natural (PMN) por hectare, o teor de sacarose, determinado segundo a metodologia descrita por Payne (1968), e a produção de açúcar por hectare, determinada multiplicando-se o teor de sacarose pela PMN.

As amostras para determinação da composição química foram obtidas da mesma forma que para a PMN, porém, utilizadas apenas cinco plantas inteiras processadas em picadora de forragem, modelo estacionário, com regulagem das lâminas para se obter partículas com tamanho médio de 1,5 $\mathrm{cm}$. A seguir foram coletadas duas alíquotas, uma para determinação do teor de FDN, FDA, hemicelulose e lignina, matéria mineral (MM) e a outra para avaliar a DRIS da FDN, que foram acondicionadas em sacos plásticos e armazenadas em refrigerador à temperatura de $-5^{\circ} \mathrm{C}$. O descongelamento foi efetuado à temperatura ambiente e a secagem foi realizada em estufas com ventilação forçada a $55^{\circ} \mathrm{C}$ por 72 horas. Após a secagem, uma alíquota das amostras foi moída em moinho de facas com peneira de $2 \mathrm{~mm}$ para avaliação da DRIS da FDN, e a outra alíquota em peneira de $1 \mathrm{~mm}$ para determinação dos teores de FDN, FDA, MM, hemicelulose e lignina.

Os teores de FDN, FDA, lignina e MM foram determinados conforme Silva e Queiroz (2002). O teor de hemicelulose foi obtido pela diferença entre o teor de FDN e FDA. A determinação da DRIS foi realizada segundo metodologia proposta por Mehrez e Ørskov (1977). Para determinação da DRIS 
utilizou-se o delineamento estatístico quadrado latino ( $4 \times 4$ ) com os tempos de incubação de 6, 24, 36 e 96 h casualizados na parcela e as variedades de cana-de-açúcar na sub-parcela. Constituindo as colunas foram casualizados os animais fistulados e nas linhas os períodos sucessivos. Isto permitiu que todas as amostras incubadas em um mesmo animal fossem retiradas ao mesmo tempo.

As amostras, moídas em moinho de facas, com peneira de $2 \mathrm{~mm}$, foram incubadas em sacos de náilon com $50 \mu \mathrm{m}$ de abertura entre malhas, medindo $5 \times 2,5 \mathrm{~cm}$. Antes de colocar as amostras nos sacos, os mesmos foram lavados e secos em estufa de ventilação forçada de ar a $55^{\circ} \mathrm{C}$, durante 24 horas. Após este período, os sacos foram colocados em dessecador, pesados a quente e identificados. Um grama de MS, de cada amostra foi colocado em cada saco obedecendo a relação entre quantidade de amostra por área de superfície do saco (15 mg de MS/ $\mathrm{cm}^{2}$ de superfície do saco), em 4 repetições, para os respectivos tempos de incubação, totalizando 384 amostras/período de avaliação. Os sacos referentes a todas as variedades, provenientes de cada bloco foram fixados ao longo de uma corrente, tendo em uma extremidade um peso e uma corda de náilon na outra. O peso com a finalidade de manter o material incubado na região ventral do rúmen, e a corda de fixar a corrente à borda superior da cânula ruminal.

Foram utilizados 4 animais fistulados no rúmen, $1 / 2$ sangue Holandês-Zebu mantidos em sistema de confinamento e alimentados 2 vezes ao dia, às 8:00 e 16:00 h, com $30 \mathrm{~kg}$ de cana-de-açúcar picada como volumoso exclusivo e $2 \mathrm{~kg}$ de ração concentrada, divididos em partes iguais e fornecidos simultaneamente duas vezes ao dia. A ração concentrada foi formulada para permitir o aporte de proteína e energia demandados para mantença, a fim de fornecer condições ruminais ideais para determinação da DRIS. Foram utilizados 7 dias como fase de adaptação e foram conduzidas as incubações.
Após o término de cada tempo de incubação, o conjunto de material foi retirado e lavado com água corrente até que a água que escorresse dos sacos estivesse clara para extração dos componentes solúveis e redução dos efeitos de contaminação por partículas e bactérias. A seguir, foram armazenados em refrigerador para posteriores análises.

Os sacos foram descongelados em bandejas de alumínio, expostas em bancadas, a temperatura ambiente, a seguir imersos em solução detergente neutra por 1 hora em fervura para determinar a DRIS da FDN. Em seguida, os sacos foram lavados em água corrente para eliminar o excesso de detergente e colocados em estufa com ventilação forçada, durante 72 horas a $55^{\circ} \mathrm{C}$ e depois colocados em dessecadores e pesados à temperatura ambiente.

Os dados referentes à DRIS da FDN foram ajustados ao seguinte modelo matemático, conforme as recomendações de Mertens (1977) e Ellis et al. (2005), com algumas modificações:

$$
\left\{\begin{array}{l}
R(t)=R(0), 0 \leq t \leq L \\
R(t)=[R(0)-I(0)] e^{-c(t-v L)}+I(0), t>L
\end{array}\right.
$$

em que:

$R(t)$ : representa o resíduo de incubação do nutriente (FDN) após determinado tempo, $\mathrm{t}(\mathrm{h})$;

$\mathrm{R}(0)$ : equivale ao resíduo observado após solubilização do material em liquido ruminal;

$c\left(h^{-1}\right)$ : correspondente à taxa de degradação da fração insolúvel mas potencialmente degradável;

L: estima o tempo de latência discreto, expresso em h;

v: é uma variável binária a qual é atribuído o valor um quando o perfil interpretado apresenta latência discreta aparente após inspeção visual, ou atribuído o valor zero, caso contrário;

$\mathrm{I}(0)$ : corresponde à fração indigerível do nutriente em estudo;

$R(0)$ - $I(0)$ : equivale à fração $B(0)$ ou fração insolúvel potencialmente degradável;

$M S-R(0)$ : representa a fração solúvel da MS, $S(0)$;

FDN - R(0): é igual a zero. 
O modelo estatístico utilizado foi o de blocos casualizados com 24 variedades e 4 repetições, segundo o seguinte modelo:

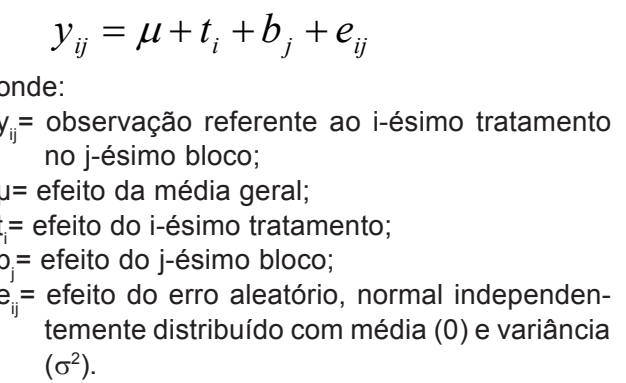

Os dados foram analisados com o auxilio do programa estatístico GENES (Cruz, 2001) e SAS (1985).

\section{RESULTADOSEDISCUSSÃO}

Na tabela I são apresentados os valores médios de produção de matéria natural, sacarose, fibra insolúvel em detergente neutro, fibra insolúvel em detergente ácido, lignina, hemicelulose, matéria mineral de cada variedade de cana-de-açúcar avaliada.

A produção de matéria natural observada no presente estudo está de acordo com os resultados obtidos por Dinardo-Miranda et al., 2002; Abreu et al., 2007. Por outro lado, diferiu dos valores detectados por Dinardo-Miranda et al., 2004; Santos et al., 2004; Oliveira et al., 2007. Devendo-se considerar as variações existentes em função das condições experimentais, as variedades estudadas, as condições edafoclimáticas, os tratos culturais dispensados em cada estudo não levados em consideração para efeito de comparação neste trabalho.

A produção de matéria natural $(49,04$ t/ ha, mínimo; 121,21 t/ha, média e 156,73 t/ha, máximo) das variedades avaliadas no presente estudo foi determinada por Carneiro Jr. ${ }^{1}$. Apesar de o valor mínimo estar entre os valores observados na $1^{\text {a }}$ soca, a média e o valor máximo na planta foram conside-

${ }^{1}$ dados não publicados. ravelmente superiores aos da $1^{\text {a }}$ soca. Da mesma forma, Landell et al. (2002) observaram para as variedades IAC86-2480 e RB 72454 no primeiro corte 129,9 e 143,5 t/ha, respectivamente; para cana soca a produção obtida foi 93,9 e $101,6 \mathrm{t} /$ ha e na $2^{\mathrm{a}}$ soca 94,3 e $106 \mathrm{t} / \mathrm{ha}$. A perda de vigor produtivo evidenciado pela redução da produtividade de ambas as variedades da cana para a primeira soca, foi de $29,7 \%$, já da primeira soca para a segunda a produtividade foi mantida, provavelmente devido a práticas de manejo e outros efeitos climáticos.

Os valores observados para produção de açúcar por hectare no presente estudo estão de acordo com os obtidos por DinardoMiranda et al., 2002. No entanto, foram inferiores aos observados por DinardoMiranda et al., 2004; Santos et al., 2004; Abreu et al., 2007.

O conteúdo de parede celular vegetal da cana-de-açúcar representado pelo teor de fibra insolúvel em detergente neutro (FDN) representa em média $45 \%$ da matéria seca, o que proporcionalmente confere a esta variável caráter de principal componente da composição química. Os resultados observados para as variedades objeto de estudo do presente trabalho (tabela I) estão próximos aos resultados encontrados na literatura para a cana-de-açúcar (Pereira et al., 2000; Fernandes et al., 2003; Azevedo et al., 2003; Andrade et al., 2004; Freitas et al., 2006; Magalhães et al., 2006; Fernandes et $a l ., 2007)$. Na alimentação e nutrição de ruminantes objetiva-se utilizar variedades que contenham menor teor de FDN em função da sua relação inversamente com o consumo alimentar (Mertens, 1987).

A variação do teor de fibra insolúvel em detergente ácido (FDA) em as variedades avaliadas concorda com os valores encontrados na literatura (Fernandes et al., 2003; Azevedo et al., 2003; Andrade et al., 2004; Freitas et al., 2006; Magalhães et al., 2006).

A lignina da parede celular é considerada responsável pela formação de uma espécie de barreira física constituindo $o$ 


\section{PRODUÇÃO E QUALIDADE DE CULTIVARES DE CANA-DE-AÇÚCAR}

complexo celulose + hemicelulose + lignina, recalcitrante aos ataques microbianos e associada à indigestibilidade dos componentes da parede celular (Van Soest, 1994). Os resultados detectados para o teor de lignina das variedades de cana-de-açúcar avaliadas estão próximos aos verificados por Andrade et al., 2004; Magalhães et al., 2006. Entretanto, são inferiores ao relatados por Pereira et al., 2000; Fernandes et al., 2003; Azevedo et al., 2003; Freitas et al., 2006. As diferenças observadas podem ser justificadas pela idade da planta no momento do corte, época de corte ou mesmo em função da característica especifica da variedade estudada para determinada substância.

Os valores obtidos para hemicelulose estão de acordo com os encontrados na literatura por Azevedo et al., 2003; Freitas et al., 2006. No entanto, Andrade et al. (2004) observaram para cana cortada aos 12 meses, valor inferior e superior, respectivamente ao menor e maior valor verificado no presen-

Tabela I. Valores médios de produção de matéria natural (PMN, t/ha), sacarose (t/ha), fibra insolúvel em detergente neutro (FDN, \%MS), fibra insolúvel em detergente ácido (FDA, $\% M S)$, lignina (LIG, \%MS), hemicelulose (HCEL, \%MS) e matéria mineral (MM, \%MS) das variedades de cana-de-açúcar. (Mean values of natural matter yield (PMN, t/ha), sucrose (t/ha), neutral detergent fiber (NDF, \%MS), acid detergent fiber (ADF, \%MS), lignin (LIG, \%MS), hemicellulose (HCEL, \%MS) and ash (MM, \%MS) of sugarcane varieties).

\begin{tabular}{|c|c|c|c|c|c|c|c|}
\hline Variedades & $\mathrm{PMN}$ & Sacarose & FDN & FDA & LIG & HCEL & MM \\
\hline SP91-1049 & 70,83 & 10,34 & 44,91 & 28,63 & 5,42 & 16,27 & 1,21 \\
\hline CB44-74 & 44,64 & 5,40 & 50,51 & 28,14 & 4,77 & 22,37 & 1,87 \\
\hline SP83-5073 & 53,81 & 7,87 & 44,16 & 26,47 & 4,33 & 17,69 & 1,12 \\
\hline RB858927 & 80,95 & 10,83 & 47,44 & 28,84 & 4,27 & 18,60 & 1,29 \\
\hline RB928064 & 84,82 & 11,24 & 48,33 & 29,92 & 5,40 & 18,40 & 1,71 \\
\hline SP83-2847 & 57,38 & 7,56 & 44,62 & 26,52 & 3,79 & 18,10 & 1,31 \\
\hline SP90-3414 & 82,20 & 10,96 & 40,50 & 25,39 & 3,71 & 15,11 & 1,12 \\
\hline SP80-1816 & 96,73 & 13,77 & 45,53 & 29,62 & 5,18 & 15,91 & 1,47 \\
\hline RB867515 & 78,21 & 10,23 & 42,34 & 25,43 & 4,43 & 16,91 & 0,86 \\
\hline RB835054 & 73,69 & 10,37 & 44,48 & 26,04 & 4,18 & 18,44 & 1,04 \\
\hline RB855536 & 96,49 & 13,09 & 41,82 & 24,66 & 3,54 & 17,16 & 1,39 \\
\hline SP79-2233 & 61,25 & 8,53 & 42,78 & 25,33 & 5,38 & 17,46 & 1,76 \\
\hline RB845210 & 86,01 & 11,48 & 41,82 & 22,46 & 4,01 & 19,37 & 1,29 \\
\hline SP80-3280 & 92,26 & 12,47 & 46,31 & 28,92 & 4,97 & 17,39 & 1,26 \\
\hline RB758540 & 97,02 & 12,79 & 48,20 & 28,41 & 4,86 & 19,78 & 1,59 \\
\hline SP90-1638 & 69,17 & 9,20 & 41,93 & 24,84 & 4,02 & 17,09 & 0,87 \\
\hline RB835486 & 81,19 & 11,53 & 45,16 & 25,75 & 4,49 & 19,41 & 1,49 \\
\hline SP80-1842 & 86,43 & 12,84 & 57,94 & 35,31 & 6,48 & 22,63 & 1,15 \\
\hline SP81-3250 & 89,52 & 12,58 & 44,58 & 27,01 & 5,55 & 17,58 & 1,28 \\
\hline SP86-155 & 42,62 & 5,79 & 44,51 & 27,76 & 5,27 & 16,75 & 0,89 \\
\hline RB72454 & 89,88 & 12,08 & 43,30 & 27,31 & 4,35 & 15,99 & 1,25 \\
\hline RB765418 & 53,46 & 6,59 & 48,04 & 29,90 & 4,93 & 18,14 & 1,35 \\
\hline RB739735 & 65,48 & 8,90 & 41,76 & 24,98 & 4,66 & 16,78 & 1,03 \\
\hline RB855113 & 88,10 & 11,35 & 47,07 & 28,69 & 4,50 & 18,39 & 1,20 \\
\hline Média & 78,81 & 10,77 & 44,78 & 26,92 & 4,46 & 18,12 & 1,25 \\
\hline Erro padrão & 19,71 & 2,77 & 5,34 & 4,14 & 1,62 & 3,19 & 0,32 \\
\hline CV (\%) & 15,4 & 15,27 & 9,56 & 13,41 & 28,44 & 15,95 & 16,83 \\
\hline
\end{tabular}




\section{PÁDUA, FONTES, THIÉBAUT, DEMINICIS, ALMEIDA E ARAUJO}

te estudo onde as canas apresentavam a mesma idade ao corte do referido trabalho.

Os resultados referentes aos teores de matéria mineral (MM) foram inferiores aos descritos na literatura (Pereira et al., 2000; Andrade et al., 2004; Magalhães et al., 2006). Porém, a participação da cana-deaçúcar como fonte de minerais para os ruminantes é muito limitada, sendo mesma deficiente em minerais como cálcio e fósforo, dos quais os ruminantes necessitam em maior quantidade.

As frações determinadas pela técnica in situ para o alimento são constituídas pela fração "B" considerada de média degradação e fração "I", representando a porção indegradável. Neste sentido, na determinação da DRIS utilizando animais fistulados no rúmen, sendo as amostras incubadas e retiradas todas de uma só vez, mantem-se as condições do ambiente ruminal favoráveis aos processos digestivos sem a perda de precisão dos resultados obtidos. Esta possibilita a situação ideal para simulação do ambiente ruminal (Van Soest, 1994).

As frações constituintes da cana-deaçúcar determinadas pela técnica in situ, permitem uma avaliação rápida e de relevância prática para a alimentação e nutrição de ruminantes, pois se quantifica a porção indigerível potencialmente degradável, a porção indegradável e a taxa com a qual ocorre a degradação da porção insolúvel potencialmente degradável no rúmen.

A taxa de degradação da fibra insolúvel em detergente neutro $\left(\mathrm{k}_{\mathrm{d}} \mathrm{FDN}\right)$ (tabela II) foi semelhante a obtida por Pereira et al. (2000) que observaram valor de $0,0341 \mathrm{~h}^{-1}$, por Azevedo et al. (2003) de $0,0400 \mathrm{~h}^{-1} \mathrm{e}$ por Fernandes et al. (2003) para as idades de corte de 487 e 549 dias, porém diferindo para idade de corte de 426 dias. No mesmo sentido, diferiu do valor observado por Freitas et al. (2006) que observaram valor médio de $0,0143 \mathrm{~h}^{-1}$. As variações respeito aos resultados obtidos no presente estudo, podem ser explicadas por razões inerentes ao animal, sua alimentação e manejo, tamanho de partícula e quantidade de amostra, o tipo de material utilizado na confecção dos sacos, ao tamanho da corda e do peso e a etapa de lavagem e processamento dos sacos que contém os resíduos das amostras após a retirada do rúmen. Porém, estas informações normalmente não são levadas em consideração para efeito de comparação de resultados o que leva a comparações generalistas que são usualmente empregadas.

Na tabela II são apresentados os valores

Tabela II. Valores médios estimados para as variáveis taxa de degradação da FDN $\left(k_{d} F D N\right)$, fração indegradável (I), fração potencialmente indegradável (B). (Mean values for the variables estimated degradation rate of NDF ( $\left.k_{d} N D F\right)$, undegradable fraction (I), potentially undegradable fraction (B)).

\begin{tabular}{lccc}
\hline Variedade & $\mathrm{k}_{\mathrm{d}} \mathrm{FDN}\left(\mathrm{h}^{-1}\right)$ & $\mathrm{I}(\%)$ & $\mathrm{B}(\%)$ \\
\hline SP91-1049 & 0,0258 & 50,48 & 49,52 \\
CB44-74 & 0,0322 & 46,58 & 53,42 \\
SP83-5073 & 0,0206 & 44,95 & 55,05 \\
RB858927 & 0,0273 & 42,46 & 57,54 \\
RB928064 & 0,0264 & 47,44 & 52,56 \\
SP83-2847 & 0,0300 & 46,91 & 53,09 \\
SP90-3414 & 0,0280 & 44,05 & 55,95 \\
SP80-1816 & 0,0424 & 45,66 & 54,34 \\
RB867515 & 0,0318 & 51,84 & 48,16 \\
RB835054 & 0,0197 & 42,30 & 57,70 \\
RB855536 & 0,0312 & 43,38 & 56,62 \\
SP79-2233 & 0,0286 & 47,84 & 52,16 \\
RB845210 & 0,0329 & 50,25 & 49,75 \\
SP80-3280 & 0,0400 & 47,94 & 52,06 \\
RB758540 & 0,0391 & 55,04 & 44,96 \\
SP90-1638 & 0,0222 & 40,62 & 59,38 \\
RB835486 & 0,0325 & 36,21 & 63,79 \\
SP80-1842 & 0,0264 & 48,08 & 51,92 \\
SP81-3250 & 0,0390 & 50,33 & 49,67 \\
SP86-155 & 0,0321 & 49,92 & 50,08 \\
RB72454 & 0,0392 & 49,04 & 50,96 \\
RB765418 & 0,0238 & 44,76 & 55,24 \\
RB739735 & 0,0214 & 45,09 & 54,91 \\
RB855113 & 0,0363 & 48,10 & 51,90 \\
Média & 0,0301 & 47,09 & 52,91 \\
Erro padrão & 0,0096 & 4,54 & 4,54 \\
CV (\%) & 26,37 & 4,93 & 4,29 \\
\hline
\end{tabular}


do perfil cinético de degradação in situ das variedades de cana-de-açúcar avaliadas. Os resultados obtidos para fração indegradável (tabela II) diferiram dos observados por Pereira et al. (2000) que verificaram 22,74\%, dos observados por Fernandes et al. (2003), que situaram-se acima de $57 \%$. O valor máximo observado no presente estudo foi de $55,04 \%$, aproximando-se do mínimo $54,5 \%$ e diferindo do máximo $61,2 \%$ observado por Azevedo et al. (2003). A fração indegradável (I) determinada pela técnica in situ denota a porção alimentar que foi incubada, passou pelos processos de adesão, ataque e digestão microbiana e permaneceu inerte, ou seja, não estaria disponível ao animal para sua nutrição. Comparativamente, quanto maior a fração indegradável e indisponível aos microrganismos ruminais, menor a fração potencialmente degradável e disponível nutricionalmente.

Os constituintes da parede celular das forrageiras (FDN), tem recebido ênfase em estudos relacionados a sua heterogeneidade e influência nos aspectos quantitativos, metabólicos e nutricionais relacionados ao consumo e a digestibilidade (Mertens, 1987; Vieira et al., 2008). A fração indigerível potencialmente degradável (B) constitui a principal fonte de energia contida na forragem e que é disponível aos microrganismos durante a digestão ruminal da forragem.

A fração B (tabela II) apresentara pronunciada variação com extremos de 44,96\% (RB758540) e 63,79\% (RB835486), o que representa uma amplitude de 18,83 pontos percentuais. Os valores detectados para fração B diferiram do observado por Pereira et al. (2000), Fernandes et al. (2003) e Azevedo et al. (2003). Por outro lado, se aproximam dos valores observados por Freitas et al. (2006). Diante do exposto, a utilização de informações referentes aos parâmetros estimados por meio da DRIS, ou seja, as frações principais constituintes da parede celular vegetal (B e I) permitem em função da variabilidade, a realização de estudos de divergência nutricional de va- riedades de cana-de-açúcar ou mesmo de melhoramento genético vegetal aplicados diretamente nos quesitos relacionados a nutrição e alimentação animal e que são demandados para cana como opção forrageira.

Foi aplicado o teste de normalidade em todas as variáveis estudadas e a distribuição delas não diferiu significativamente da distribuição normal ao nivel de $5 \%$ de probabilidade.

Diante da normalidade verificada para a distribuição das variáveis estudadas, pressupõe-se uma distribuição normal multivariada. Na sequência, foi realizada a análise de multicolinearidade, entre as variáveis, que permitiu a explicação da variabilidade total apartir de um número reduzido de variáveis. Baseando-se no resultado da análise de multicolinearidade foi realizada a análise de variância para as variáveis selecionadas e as variedades foram agrupadas pelo teste de Scott-Knott ao nível de $5 \%$ de probabilidade.

Ao proceder-se ao teste de componentes principais tiveram-se como premissas que a importância relativa dos componentes principais decresce do primeiro para o último, tem-se que os últimos componentes são responsáveis pela explicação de uma fração mínima da variância total disponível. As variáveis passíveis de descarte em um estudo de divergência são aquelas invariantes entre as estudadas ou redundantes, por estarem correlacionadas com outras variáveis. A possibilidade de descarte das variáveis que contribuem pouco para a discriminação do material avaliado permite a redução da mão-de-obra, do tempo e do custo despendido na experimentação (Cruz e Regazzi, 1997).

A contribuição das variáveis para discriminar os grupos de variedades foi avaliada em duas etapas: agrupamento 1 e 2 apresentadas na tabela III. O agrupamento 1 foi realizado com as sete variáveis restantes após a eliminação das variáveis que provocaram multicolinearidade severa, o agrupamento 2 realizado com as variáveis 
Tabela III. Contribuição das variáveis para discriminação das variedades por grupo. (Contribution of variables for discrimination of varieties of group).

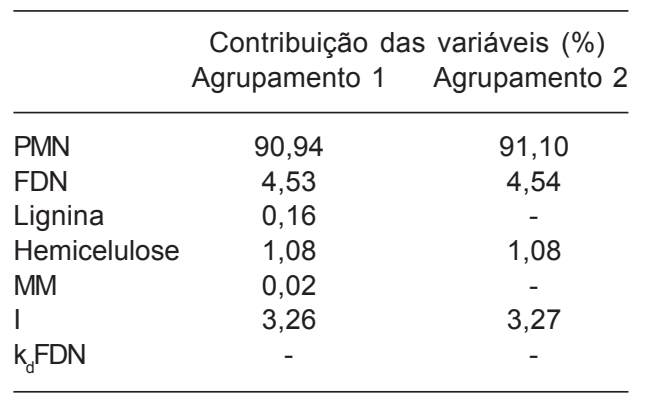

PMN: produção de materia natural (t/ha); FDN: fibra em detergente neutro; MM: matéria mineral; I: fração indegradável; $k_{\mathrm{d}} F D N$ : taxa de degradação da fração insolúvel potencialmente degradável.

que mais contribuíram para discriminar as variedades.

A amplitude existente entre a produção de materia natural (PMN) das variedades estudadas acompanhada do desvio padrão (tabela I) possivelmente podem explicar a maior contribuição desta variável (tabela III) para discriminação dos grupos através da análise de componentes principais (tabela IV). Uma vez que na análise por componentes principais são utilizados os primeiros componentes quando esses envolvem pelo menos $80 \%$ da variação total (Cruz et al., 2004). Comportamento este observado no presente estudo onde os primeiros componentes (PMN e FDN) explicaram 95,47 e $95,65 \%$ (tabela III) para o primeiro e segundo agrupamentos, respectivamente.

Na tabela III são apresentados os valores das contribuições das variáveis para discriminação das variedades. A variável produção de açúcar por ser uma função da produção de matéria natural, teve comportamento semelhante para as variedades estudadas, o teor de FDA por estar contido no teor de FDN e a fração B por ser fruto da diferença entre o total e a fração I (tabela I) foram descartados por apresentarem correlação alta e positiva com as respectivas frações citadas e que foram mantidas na análise de agrupamento.

A contribuição para discriminação das variedades em grupos pela variável FDN foi de 4,53 e $4,54 \%$ (tabela III) para o primeiro e segundo agrupamento, respectivamente. Sendo o segundo componente principal que mais contribui para discriminar os grupos, a manutenção de um componente que comparativamente contribua pouco em comparação aos demais, no exemplo em questão a PMN, reside na sua importância para área de estudo preconizada.

A contribuição das variáveis lignina e

Tabela IV. Grupos de variedades de canade-açúcar e médias das variáveis em cada grupo. (Varieties of sugarcane and averages of variables in each group).

\begin{tabular}{|c|c|c|c|}
\hline & & Grupos* & \\
\hline & I & & III \\
\hline & RB758540 & & \\
\hline & SP80-1816 & & \\
\hline & RB855536 & & \\
\hline & SP80-3280 & & \\
\hline & RB72454 & SP83-2847 & \\
\hline & SP81-3250 & SP91-1049 & SP83-5073 \\
\hline & RB855113 & SP90-1638 & RB765418 \\
\hline & SP80-1842 & RB739735 & CB44-74 \\
\hline & RB845210 & SP79-2233 & SP86-155 \\
\hline & RB928064 & & \\
\hline & SP90-3414 & & \\
\hline & RB835486 & & \\
\hline & RB858927 & & \\
\hline & RB867515 & & \\
\hline & RB835054 & & \\
\hline $\mathrm{PMN}^{1}$ & 88,10 & 64,29 & 53,57 \\
\hline $\mathrm{FDN}^{2}$ & 44,96 & 43,02 & 45,87 \\
\hline $1^{2}$ & 47,14 & 47,41 & 46,56 \\
\hline Hemicelulose & $2^{2} \quad 18,17$ & 16,98 & 18,60 \\
\hline $\mathrm{k}_{\mathrm{d}}^{3}$ & 0,0322 & 0,0231 & 0,0289 \\
\hline
\end{tabular}

*Grupos formados pelo teste de Scott Knott ao nível de $5 \%$ de significância; ${ }^{1}$ ton $^{*} \mathrm{ha}^{-1}{ }^{2}{ }^{2} \% \mathrm{MS} ;{ }^{3} \mathrm{~h}^{-1}$. 
MM no agrupamento 1 foram mínimas ao passo que com a eliminação das mesmas e da variável $\mathrm{k}_{\mathrm{d}} \mathrm{FDN}$ que não apresentou contribuição discriminante o aumento nas demais variáveis mantidas no agrupamento 2 foi de pequena magnitude. Freitas et al. (2006) em avaliação da divergência nutricional entre variedades de cana-de-açúcar estabeleceu o limite mínimo de contribuição de uma variável para o poder total de discriminação dos grupos de $10 \%$. Por outro lado ao contrário do ocorrido no presente estudo, quando o referido autor eliminou as variáveis avaliadas que não contribuíam para discriminar os grupos de variedades e submeteu as variáveis mantidas novamente ao teste de agrupamento, as que apresentaram maior contribuição no agrupamento 1 sofreram aumento percentual de contribuição de $6,41 \%$ no agrupamento 2 . O aumento observado no presente estudo para as contribuições fornecidas pelas variáveis para discriminação dos grupos de variedades pode ser explicado pela pequena magnitude da variação das demais variáveis em detrimento a da variável PMN. Como critério de escolha de uma variedade de cana-de-açúcar em detrimento a outra para alimentação e nutrição de ruminantes, vários são os parâmetros a serem considerados, como por exemplo, elevada produção de biomassa, baixo teor de FDN e proporcionalmente elevado teor de carboidratos solúveis, baixa fração indegradável e alta taxa de degradação.

As variedades avaliadas apresentaram como característica principal que as classificaram em grupos distintos a produção de matéria natural, parâmetro este considerado como de maior importância em detrimento aos demais citados, em função de não haver justificativa de recomendação de uma variedade para alimentação e nutrição animal ou mesmo para produção de açúcar e álcool que apresente baixa produção de biomassa.

$\mathrm{Na}$ tabela IV são apresentadas as variedades distribuídas por grupo com as médias das variáveis utilizadas no agrupamento 2 (tabela III) e a taxa de degradação $\mathrm{k}_{d} \mathrm{FDN}$. A variável $\mathrm{k}_{\mathrm{d}} \mathrm{FDN}$ por mais que não tenha contribuído para discriminação dos grupos de variedades foi incluída em função de sua importância para avaliação de uma variedade de cana-de-açúcar destinada a alimentação animal. Os grupos I, II e III foram constituídos por 15,4 e 5 variedades, respectivamente.

A queda na produtividade ao longo dos cortes é inevitável na cana-de-açúcar. A redução no vigor produtivo está associada às práticas de colheita, tratos culturais, clima e compactação, estando a vida útil de uma cultura bem conduzida em torno de 4 anos, no máximo 8 anos. Dentre as características de maior relevância que uma variedade de cana-de-açúcar deve apresentar para justificar seu cultivo para qualquer fim, está a produção de matéria natural. Neste sentido, no presente estudo a maioria das variedades avaliadas teve comportamento semelhante estatisticamente para o componente de maior importância para explicar a divergência entre os grupos a PMN fato este que pode ser evidenciado pelo maior número de variedades que compuseram o grupo de maior média para esta variável.

Na tabela IV são apresentados os grupos formados pelas variedades de cana-deaçúcar avaliadas seguidos dos valores médios das variáveis utilizadas na análise de agrupamento.

As variedades foram agrupadas em três grupos pela análise de agrupamento segundo o critério adotado pela análise de componentes principais (tabela IV). Entre as variedades estudadas no tocante a cinética de degradação da FDN a variedade RB 835486 se destacou por apresentar menor fração indegradável(I) e proporcionalmente maior fração potencialmente degradável (B), embora a diferença entre as taxas de degradação $\left(\mathrm{k}_{\mathrm{d}} \mathrm{FDN}\right)$ das variedades estudadas não tenha sido elevada, a $\mathrm{k}_{\mathrm{d}} \mathrm{FDN}$ da referida variedade apresentou valor supe- 
PÁDUA, FONTES, THIÉBAUT, DEMINICIS, ALMEIDAEARAUJO

rior a média obtida no estudo. Desta forma, as características pertinentes a RB 835486 , como elevada produção de biomassa e açúcar por unidade de área, teor de FDA abaixo da média obtida, contribuem para justificar uma menor fração indegradável encontrada para a variedade.

A variabilidade nas características de produção de biomassa e açúcar, composição química e DRIS invariavelmente ocorre (Freitas et al., 2006). Todavia, ponderações sobre o conjunto de variáveis que qualificam um material de cana-de-açúcar devem ser feitas com critério técnico a fim de qualificar variedades para a alimentação animal. A variedade RB 855536 apresentou atributos desejáveis para utilização na alimentação animal, elevada produção de biomassa associada a baixos teores de constituintes da parede celular, carboidratos fibrosos $(\mathrm{CF})$ de degradação lenta, o que proporcionalmente se opõe ao teor de carboidratos não fibrosos (CNF) que são rapidamente fermentados no rúmen e de fácil aproveitamento pelo animal.

O critério adotado para escolha de um material de cana-de-açúcar destinado a alimentação animal, deve estar respaldado numa série de fatores que permitam ao técnico avaliar a potencialidade dos materiais disponíveis, não sendo recomendada a utilização de características isoladas. Portanto, uma variedade de cana-de-açúcar por mais que apresente, por exemplo, reduzido teor de $\mathrm{CF}$ e conseqüentemente

\section{BIBLIOGRAFIA}

Abreu, J.B.R., Almeida, J.C.C., Mello, W.A., Pereira, V.V., Ferreira, M.C.M., Marques, R.A.F.S. e Oliveira, A.J. 2007. Produção, características morfológicas e de maturação de cultivares de cana-de-açúcar com diferentes ciclos de amadurecimento para uso na alimentação animal na região de Barbacena-MG. Bol Ind Anim, 64: 115-121.

Andrade, J.B., Ferrari Junior, E., Possenti, R.A., Otsuk, I.P., Zimback, L. e Landell, M.G.A. 2004. elevado teor de CNF desejáveis nutricionalmente, não deve ser recomendada para cultivo se a mesma não apresentar elevada produção de matéria natural, o que se feito aumentaria o custo por tonelada de material forrageiro produzido por área.

A variedade SP80-1842, popularmente conhecida por pé duro por apresentar consistência demasiadamente dura quando comparada com outras variedades, apesar de ter apresentado elevado teor de CF o que proporcionalmente caracteriza reduzido teor de CNF, apresentou elevada produção de biomassa e açúcar que são fatores importantes para serem levados em consideração no momento de escolha do material forrageiro de cana-de-açúcar. Os teores de FDA e lignina observados na referida variedade encontram-se entre os maiores obtidos no presente estudo, fatores que dão suporte para justificar a $\mathrm{k}_{\mathrm{d}} \mathrm{FDN}$ abaixo da média.

\section{CONCLUSÕES}

A análise de agrupamento possibilitou a formação de três grupos de variedades de cana-de-açúcar, com características distintas. A produção de matéria natural foi a variável que teve a maior contribuição para discriminar a divergência e agrupar as variedades estudadas. As variedades RB855536, RB 835486 e SP80-1842 em função das variáveis avaliadas, de forma conjunta, mostraram-se mais promissoras para a alimentação de ruminantes.
Composição química de genótipos de cana-deaçúcar em duas idades, para fins de nutrição animal. Bragantia, 63: 341-349.

Azevedo, J.A.G., Pereira, J.C., Queiroz, A.C., Carneiro, P.C.S., Lana, R.P., Barbosa, M.H.P., Fernandes, A.M. e Rennó, F.P. 2003. Avaliação da divergência nutricional de variedades de cana-de-açúcar (Saccharum spp.). Rev Bras Zootecn, 32: 1431-1442.

Cruz, C.D. 2001. Programa genes: aplicativo

Archivos de zootecnia vol. 61, núm. 235, p. 384. 


\section{PRODUÇÃO E QUALIDADE DE CULTIVARES DE CANA-DE-AÇÚCAR}

computacional em genética e estatística. Editora da UFV. Viçosa. $648 \mathrm{pp}$.

Cruz, C.D. e Regazzi, A.J. 1997. Modelos biométricos aplicados ao melhoramento genético. $2^{\mathrm{a}}$ ed. UFV. Viçosa. $390 \mathrm{pp}$.

Cruz, C., Regazzi, A.J. e Carneiro, P.C.S. 2004. Modelos biométricos aplicados ao melhoramento genético. $3^{\mathrm{a}}$ ed. UFV. Viçosa. Vol. 1. 480 pp.

Dinardo-Miranda, L.L., Coelho, A.L. e Ferreira, J.M.G. 2004. Influência da época de aplicação de inseticidas no controle de Mahanarva fimbriolata (Stål) (Hemiptera: Cercopidae), na qualidade e na produtividade da cana-deaçúcar. Neotrop Entomol, 33: 91-98.

Dinardo-Miranda, L.L., Garcia, V. e Parazzi, V.J. 2002. Efeito de inseticidas no controle de Mahanarva fimbriolata (Stål) (Hemiptera: Cercopidae) e de nematóides fitoparasitos na qualidade tecnológica e na produtividade da cana-de-açúcar. Neotrop Entomol, 31: 609614.

Ellis, W.C., Mahlooji, M. and Matis, J.H. 2005. Models for estimating parameters of neutral detergent fiber digestion by ruminal microorganisms. J Anim Sci, 83: 1591-1601.

Fernandes, A.M., Queiroz, A.C., Pereira, J.C., Lana, R.P., Barbosa, M.H.P., Fonseca, D.M. Detmann, E., Cabral, L.S., Pereira, E.S. e Vittori, A. 2003. Composição químico-bromatológica de variedades de cana-de-açúcar (Saccharum spp.) em função dos ciclos de produção precoce e intermediário e da idade de corte. Rev Bras Zootecn, 32: 977-985.

Fernandes, A.R.M., Sampaio, A.A.M., Henrique, W., Perecin, D., Oliveira, E.A. e Túllio, R.R. 2007. Avaliação econômica e desempenho de machos e fêmeas Canchim confinados, recebendo dietas com silagem de milho ou com cana-deaçúcar e grãos de girassol. Rev Bras Zootecn, 36: 855-864.

Freitas, A.W.P., Pereira, J.C., Rocha, F.C., Detmann, E., Barbosa, M.H.P., Ribeiro, M.D. e Costa, M.G. 2006. Avaliação da divergência nutricional de genótipos de cana-de-açúcar (Saccharum spp.). Rev Bras Zootecn, 35: 229-236.

Landell, M.G.A., Campana, M.P., Silva, M.A., Figueiredo, P., Dinardo-Miranda, L.L., Bidoia, M.A.P., Vasconcelos, A.C.M., Prado, H., Xavier, M.A., Martins, A.L.M., Kanthack, R.A.D., Cavichioli, J.C. e Gallo, P.B. 2002. Avaliação do potencial agroindustrial de genótipos de canade-açúcar colhidos no início da safra, na região Centro-Sul do Brasil. Anais... $8^{\circ}$ Congresso Nacional da Sociedade dos Técnicos Açucareiros e Alcooleiros do Brasil, Recife - PE. $8^{\circ}$ Congresso Nacional da STAB. Recife - PE: STAB, 8: 349-354.

Magalhães, A.L.R., Campos, J.M.S., Cabral, L.S., Mello, R., Freitas, J.A., Torres, R.A., Valadares Filho, S.C. e Assis, A.J. 2006. Cana-de-açúcar em substituição à silagem de milho em dietas para vacas em lactação: Parâmetros digestivos e ruminais. Rev Bras Zootecn, 35: 591-599.

Mehrez, A.Z. and Ørskov, E.R. 1977. A study of the artificial fiber bag technique for determining the digestibility of feeds in the rumen. J Agric Sci, 88: 645-665.

Mertens, D.R. 1977. Dietary fiber components: relationship to the rate and extent of ruminal digestion. Fed Proc, 36: 187-192.

Mertens, D.R. 1987. Predicting intake and digestibility using mathematical models of ruminal function. J Anim Sci, 64: 1548-1558.

Oliveira, R.A., Daros, E., Zambon, J.L.C., Weber, H., Ido, O.T., Bespalhok-Filho, J.C., ZuffellatoRibas, K.C. e Silva, D.K.T. 2007. Área foliar em três cultivares de cana-de-açúcar e sua correlação com a produção de biomassa. Pesqui Agropecu Trop, 37: 71-76.

Payne, J.H. 1968. Sugar cane factory analytical control. Amsterdam, Elsevier. 190 pp.

Pereira, E.S., Queiroz, A.C., Paulino, M.F., Cecon, P.R., Valadares Filho, S.C., Miranda, L.F., Fernandes, A.M. e Cabral, L.S. 2000 Determinação das frações protéicas e de carboidratos e taxas de degradação in vitro da cana-de-açúcar, da cama de frango e do farelo de algodão. Rev Bras Zootecn, 29: 1887-1893.

Santos, M.S.M., Madalena, J.A., Soares, L., Ferreira, P.V. e Barbosa, G.V.S. 2004 Repetibilidade de características agroindustriais em cana-de-açúcar. Pesqui Agropecu Bras, 39: 301-306.

SAS. 1985. SAS/STAT. User's guide (Release 6.03). SAS Inst. Inc. Cary, NC.

Silva, D.J. e Queiroz, A.C. 2002. Análise de alimentos: métodos químicos e biológicos. Impr. Univ. UFV. Viçosa, MG. 235 pp.

Van Soest, P.J. 1994. Nutritional ecology of the ruminant. $2^{\text {nd }}$ ed. Cornell University Press. 


\section{PÁDUA, FONTES, THIÉBAUT, DEMINICIS, ALMEIDA E ARAUJO}

Ithaca. $476 \mathrm{pp}$.

Vieira, R.A.M., Tedeschi, L.O. and Cannas, A. 2008. A generalized compartmental model to estimate the fibre mass in the ruminoreticulum:

2. Integrating digestion and passage. $J$ Theor Biol, 255: 357-368.

Archivos de zootecnia vol. 61, núm. 235, p. 386. 